\title{
Resistance Spot Welding Parameters Optimal Selection for Automotive Steel Plate
}

\author{
Tang Ke*, Liang Cui, Zhou Ping \\ SAIC-GM-Wuling Auto Co., Ltd., Chongqing, P. R .China
}

\section{Email address:}

ke.tang@sgmw.com.cn (Tang Ke), cuil.liang@sgmw.com.cn (Liang Cui), pingl.zhou@sgmw.com.cn (Zhou Ping)

\section{To cite this article:}

Tang Ke, Liang Cui, Zhou Ping. Resistance Spot Welding Parameters Optimal Selection for Automotive Steel Plate. International Journal of Systems Engineering. Vol. 2, No. 1, 2018, pp. 36-41. doi: 10.11648/j.ijse.20180201.18

Received: June 26, 2018; Accepted: July 19, 2018; Published: August 18, 2018

\begin{abstract}
In welding workshop, multi plate lapping is used to resistance welding usually, but so many uncertainty factors are there in welding process. In order to use less test times to meet production requirements and solve the welding nugget problem of multilayered panel lap, the optimizing welding parameter for 3 layer of low carbon steel plate with thickness of $0.8 \mathrm{~mm}+1.4 \mathrm{~mm}$ $+1.8 \mathrm{~mm}$ was found in this paper. Experimental results show that: the welding current 9.6/8.8/11.1 KA, welding time 5/19/5 CY, electrode pressure $3 \mathrm{kn}$ is suitable for 3 layer of low carbon steel plate with thickness of $0.8 \mathrm{~mm}+1.4 \mathrm{~mm}+1.8 \mathrm{~mm}$, multiple-pulse welding parameter is appropriate for multilayered panel lap, and diameter of nugget on each layer can achieve $6 \mathrm{~mm}$.
\end{abstract}

Keywords: Resistance Spot Welding, Welding Parameters, Nugget Size, Welding Quality

\section{Introduction}

Resistance spot welding is the most common connection method in the automobile manufacturing industry. [1]. There are more than 5,000 solder joints in the mini-car body such as the body floor, roof, front body, etc. [2-7], different areas bear the energy absorption in the event of a collision, connection, support and other functions. [8-9]. The actual application needs to connect different thickness, different material of steel plate for welding. [10-13]. Currently, two-layer or three-layer laps with different strengths and thicknesses have occurred in the same station while the resistance spot welding process parameters are difficult to apply to. [14-15].

This article takes the $1^{\text {st }}$ station of the front body area in Wuling Hongguang S' production line (this station welds the left front beam welded part and the front plate welding assembly) as the research object, which provides new ideas and methods for different overlapping resistance spot welding parameters selection of Wuling Hongguang S.

\section{Materials and Methods}

Taking Obara integrated resistance spot welding machine (Model: ST21, rated power 180KVA), supporting X-type manual welding gun (Model: UXH-C9625) for welding, as shown in Figure 1.

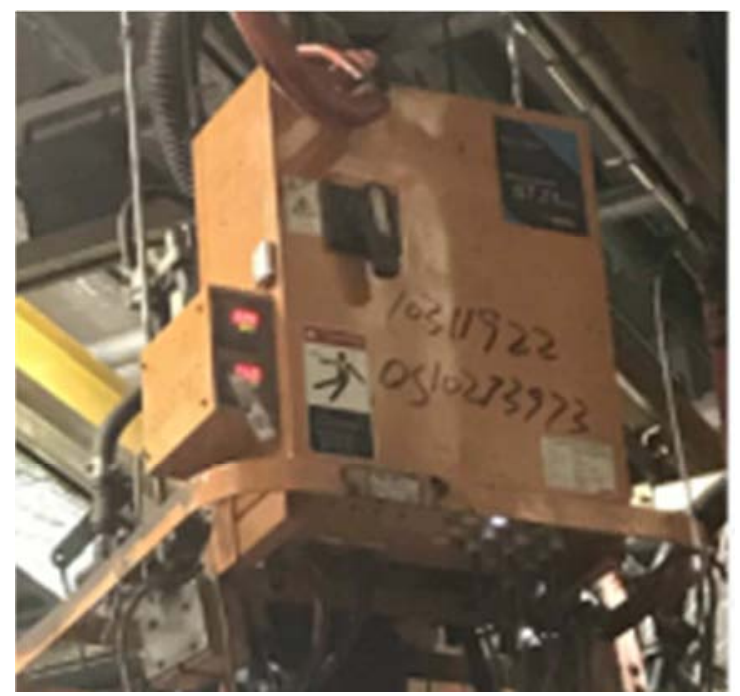




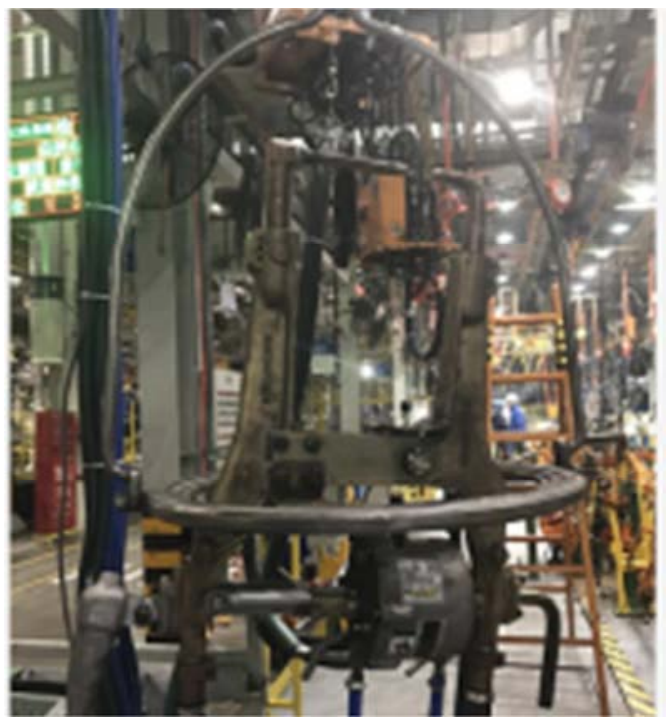

Figure 1. Test with resistance welding machine and hand gun.

The front left girder and dash panel parts are all Baosteel BLD low-carbon steel plates and table 1 shows the chemical composition of the test steel plate. A total of 11 welding spots are lapped between the front girder and the dash panel, among them, 10 lapping pads for two plates, $0.8 \mathrm{~mm}$ thick and 1.2 $\mathrm{mm}$ thick, and three welding lapping plates with a plate thickness of $0.8 \mathrm{~mm}+1.4 \mathrm{Mm}+1.8 \mathrm{~mm}$. As there are two-layer plates and three-layer plates, test is processed as follows: Firstly, taking the same plate and thickness to simulate three-layer plate overlap, choosing different welding parameters to test on three-layer plates in order to obtain welding parameters with different thickness and further define the process parameters that meet the technical requirements. Then verify the left front girder and the dash panel connection area to obtain the final process parameters.

Table 1. The chemical composition of the test plate.

\begin{tabular}{lllllll}
\hline \multirow{2}{*}{ brand } & \multicolumn{6}{c}{ Analysis of chemical composition (melting)\% (mass fraction) } \\
\cline { 2 - 7 } & $\mathbf{C}$ & Mn & P & S & Alt & Ti \\
\hline BLCa & $\leq 0.10$ & $\leq 0.05$ & $\leq 0.035$ & $\leq 0.025$ & $\geq 0.015$ & - \\
BLDa & $\leq 0.08$ & $\leq 0.45$ & $\leq 0.030$ & $\leq 0.025$ & $\geq 0.015$ & - \\
BUSD & $\leq 0.0010$ & $\leq 0.45$ & $\leq 0.025$ & $\leq 0.020$ & $\geq 0.015$ & \\
BUFD & $\leq 0.008$ & $\leq 0.40$ & $\leq 0.020$ & $\leq 0.020$ & $\geq 0.015$ & \\
BSUFD & $\leq 0.006$ & $\leq 0.30$ & $\leq 0.020$ & $\leq 0.020$ & $\geq 0.015$ & \\
\hline
\end{tabular}

A. Allows adding $\mathrm{Nb}$ or $\mathrm{Ti}$

B. Allows $\mathrm{Nb}$ to replace part of $\mathrm{Ti}$, with total content of $\mathrm{Nb}$ and $\mathrm{Ti}$ is not greater than $0.20 \%$

According to the leading plate thickness of the overlapping parts, refer to the "Suggested Value of SAW-GM Wuling Resistance Spot Welding Parameters" to select the resistance spot welding process parameters for the test. Table 2 shows the initial process parameters for resistance spot welding.

Table 2. The initial process parameters of resistance spot welding.

\begin{tabular}{|c|c|c|c|c|c|c|}
\hline Preloading time /ms & Warm up time /ms & Welding current /KA & pulse & Welding time /CY & Electrode pressure /KN & Hold time /ms \\
\hline 50 & 50 & 8.5 & 1 & 9 & 3 & 120 \\
\hline
\end{tabular}

\section{Experimental Results and Discussion}

\subsection{The Influence of the Initial Welding Process Parameters on Welding}

Three test pieces $(0.8 \mathrm{~mm}+1.4 \mathrm{~mm}+1.8 \mathrm{~mm})$ with the same plate, thickness, and process were used. According to the welding process parameters in Table 2, the welding process was tested by selecting the current $8.5 \mathrm{KA}$, electrode pressure $3 \mathrm{KN}$, and welding time $9 \mathrm{CY}$. The heat affected zone size of the solder joint was measured with a vernier caliper to be
$8.59 \mathrm{~mm}$, as shown in Figure 2 (a). After the welded test piece was torn, there was a welding nugget (size $4.86 \mathrm{~mm}$ ) at the overlap of the $0.8 \mathrm{~mm}+1.4 \mathrm{~mm}$ plate, as shown in Figure $2(\mathrm{~b})$; but the $1.4 \mathrm{~mm}+1.8 \mathrm{~mm}$ plate lap joints did not form a nugget, tearing the solder joints after the brittle fracture surface was in a particle state, as shown in Figure 2 (c);

The test results show that the initial welding process parameters are not applicable to the actual lap state of the site, and the welding process parameters need to be adjusted one by one so that the welding of the three-layer plate meets the requirements of the welding nugget.
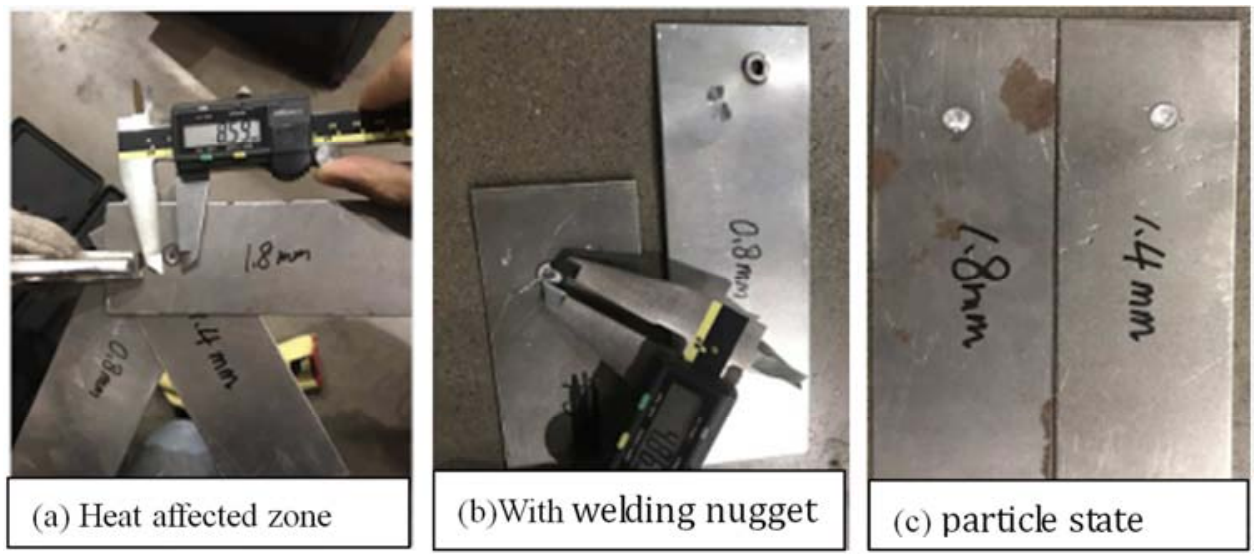

Figure 2. Nugget size of the solder joint using the initial welding process parameters. 


\subsection{Left Front Girder Welding Test and the Dash Panel Connection Area}

The main factors influencing the nugget size of the solder joints of the test piece are welding current (KA), welding time (CY), electrode pressure $(\mathrm{KN})$ and pulse, and other parameters remain unchanged. The electrode of this test adopts a spherical electrode cap and the dimension of the end face is $\varphi 7 \mathrm{~mm}$, and the process parameters are tested in a one-by-one comparison. The welding process parameters are shown in Table 3.

Table 3. Test with welding process parameters.

\begin{tabular}{lllll}
\hline \multirow{2}{*}{ No. } & Welding process parameters & & Electrode pressure $/ \mathbf{K N}$ & pulse \\
\cline { 2 - 5 } & Welding current $/ \mathbf{K A}$ & Welding time $/ \mathbf{C Y}$ & 3.0 & 1 \\
\hline Original Data & 8.5 & 9 & 3.0 & 1 \\
Experiment 2 & 10.0 & 9 & 3.0 & 1 \\
Experiment 3 & 10.0 & 14 & 3.0 & 2 \\
Experiment 4 & $7.8 / 10.0$ & $7 / 14$ & 3.8 & 2 \\
Experiment 5 & $7.8 / 10.0$ & $7 / 14$ & 3.0 & 3 \\
Experiment 6 & $8.8 / 11.1 / 9.6$ & $5 / 19 / 5$ & & \\
\hline
\end{tabular}

\subsubsection{Experiment 2}

While maintaining the welding time and electrode pressure constant, increase the welding current to $10.0 \mathrm{kA}$, Table 3 . After tearing the welded test piece, there is a welding nugget at the lap joint of the $0.8 \mathrm{~mm}+1.4 \mathrm{~mm}$ plate. The size of the nugget is $\varphi 5.69 \mathrm{~mm}$, as shown in Figure 3 (a); but the $1.4 \mathrm{~mm}+1.8 \mathrm{~mm}$ plate joints did not form a nugget, tearing the solder joints after the brittle fracture surface was in a particle state, as shown in Figure 3 (b).

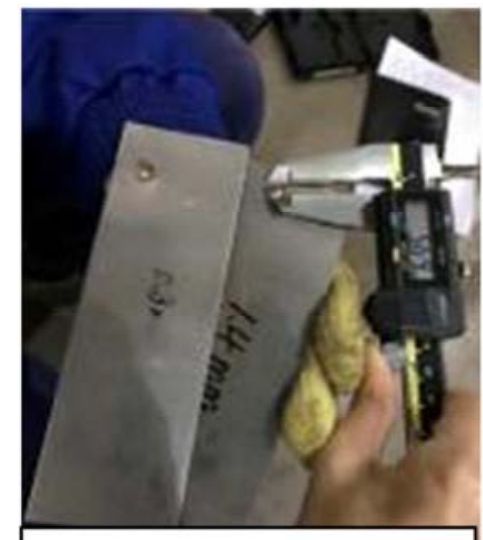

(a) welding nugget
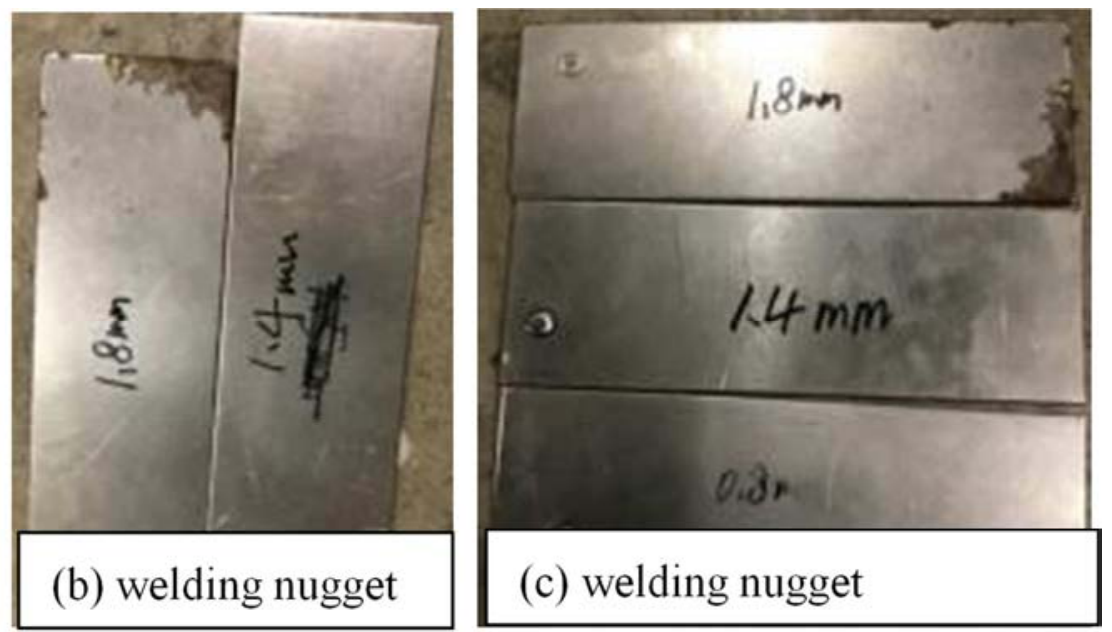

Figure 3. Nugget size of test 2.

\subsubsection{Experiment 3}
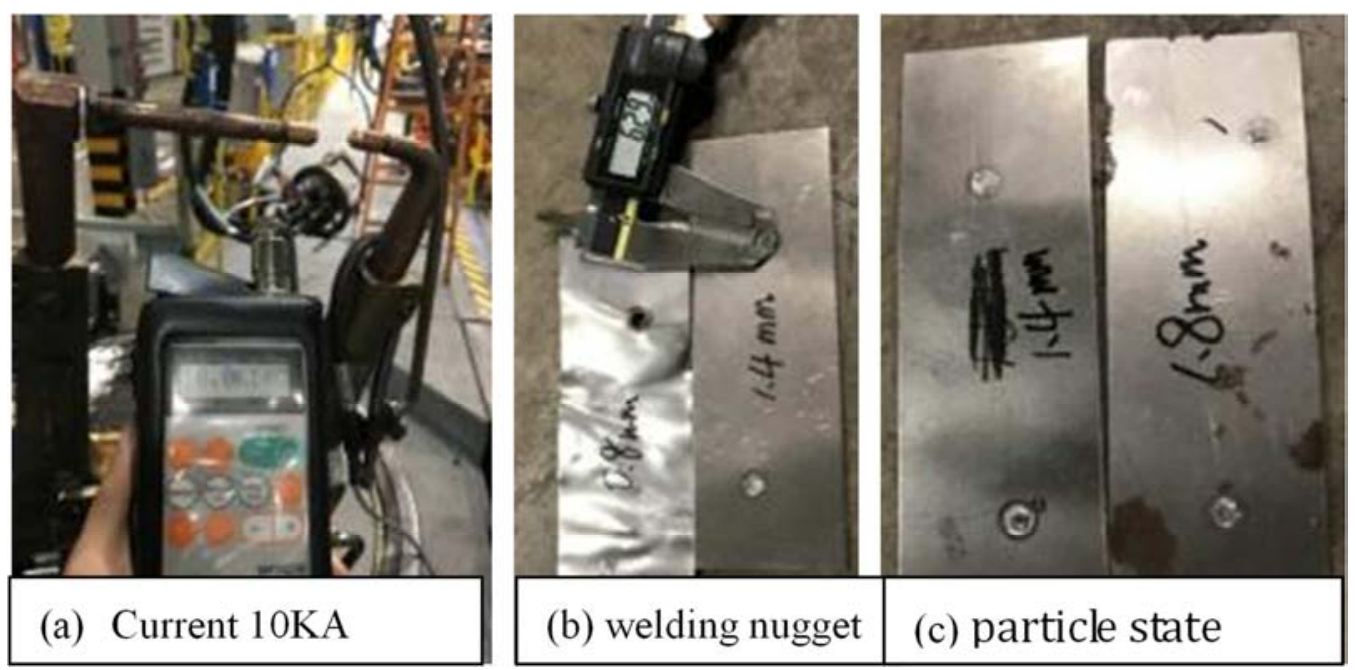

Figure 4. Nugget size of test 3. 
The welding current was maintained at $10.0 \mathrm{kA}$, the welding time was increased to $14 \mathrm{cy}$, and the electrode pressure was maintained at $3.0 \mathrm{kN}$, Table 3 . After the welding test piece was torn, there was a welding nugget at the overlap of the $0.8 \mathrm{~mm}+1.4 \mathrm{~mm}$ plate, but the nugget still did not form at the overlap of the $1.4 \mathrm{~mm}+1.8 \mathrm{~mm}$ plate, and the brittle fracture of the welding spot showed the particle state, as shown in the figure 4 (c) shows. Because the thickness of the three-layer plate is quite different, and the welding parameter nugget that meets the standard cannot be obtained by gradually increasing the single item of welding parameters, therefore, we have considered the selection of two welding pulses to increase the preheat welding before welding.

\subsubsection{Experiment 4}

Based on the results of the first three tests, we selected two pulses for testing. The first pulse: the welding current $7.8 \mathrm{KA}$,
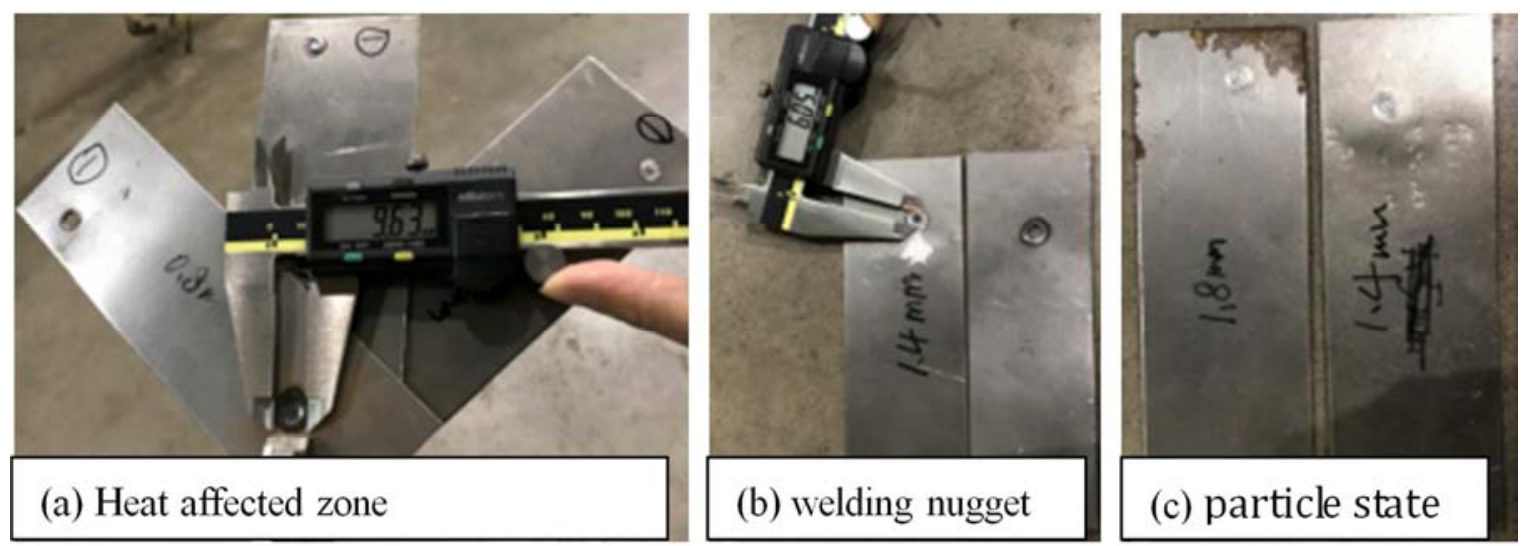

Figure 5. Nugget size of test 4.

\subsubsection{Experiment 5}

Based on the test 4 , we used the parameters of the electrode pressure to $3.8 \mathrm{KN}$ to verify the welding test piece under the condition that the welding current and welding time remain unchanged. The heat affected zone size of the solder joint is $\varphi 10.75 \mathrm{~mm}$ up to the standard upper limit, as shown in Figure 6 (a); after tearing the solder joint, there is a nugget at the the welding time $7 \mathrm{cy}$; the second pulse: the welding current $10.0 \mathrm{KA}$, the welding time $14 \mathrm{cy}$, the electrode pressure remains unchanged at $3.0 \mathrm{KN}$, Table 3 . After welding is completed, the heat affected zone of the solder joint becomes significantly larger, and the diameter is $\varphi 9.6 \mathrm{~mm}$, as shown in Figure 5 (a); after the welded test specimen is torn, there is a welding nugget at the overlap of the $0.8 \mathrm{~mm}+1.4 \mathrm{~mm}$ plate. The size of the nugget is $\varphi 6.05 \mathrm{~mm}$, as shown in Figure 5 (b); no nugget is formed at the overlap of the $1.4 \mathrm{~mm}+1.8 \mathrm{~mm}$ plate, and the brittle fracture of the solder joint indicates the particle state, but the shear stress is significantly greater than that of the single pulse. The parameters of the plate solder joints are large, as shown in Figure 5 (c). In general, this process parameter does not meet the specified nugget size requirements.

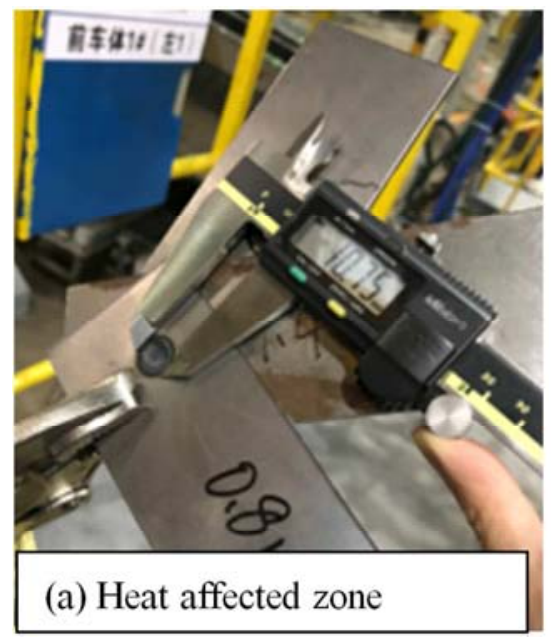

(a) Heat affected zone

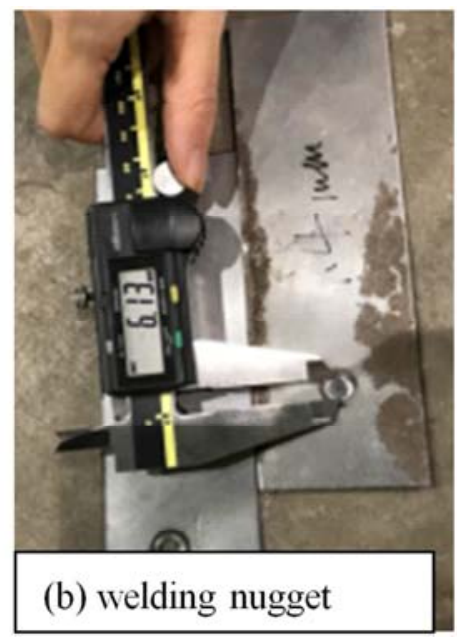

Figure 6. Nugget size and of test 5. overlap of the $0.8 \mathrm{~mm}+1.4 \mathrm{~mm}$ plate and increases to $\varphi 6.13 \mathrm{~mm}$, as shown in Figure 5 (b); but there is still no obvious nugget formed at the overlap of the $1.4 \mathrm{~mm}+1.8 \mathrm{~mm}$ plate, as shown in Figure 5 (b); if the welding current, welding time or electrode pressure is separately increased, It is difficult to produce obvious results, and there is a risk of overheating in the heat-affected zone of the solder joint. 


\subsubsection{Experiment 6}

On the basis of test 5 , taking into account the number of welds in this station and the requirements for production tempo, we chose the soft specifications commonly used in welding parameters, increased it to 3-pulse welding parameters, and increased the preheating process and main The welding nugget holding process and welding parameters are shown in Table 3. The first pulse: the welding current $8.8 \mathrm{KA}$, the welding time $5 \mathrm{cy}$; the second pulse: the welding current $11.1 \mathrm{KA}$, the welding time $19 \mathrm{cy}$; the third pulse: the welding current $9.6 \mathrm{KA}$, the welding time $5 \mathrm{cy}$; the electrode pressure is maintained at $3.0 \mathrm{KN}$. After tearing the solder joints, welding nuggets existed on the $0.8 \mathrm{~mm}+1.4 \mathrm{~mm}$ plate, and the measured nugget size was $\varphi 6.19 \mathrm{~mm}$, as shown in Figure 7 (a); there was obvious welding at the overlap of the $1.4 \mathrm{~mm}+1.8 \mathrm{~mm}$ plate. The nugget, measured nugget size is $\varphi 6.82 \mathrm{~mm}$, as shown in Figure 7 (b); and there are obvious nuggets on both sides of the middle side plate $(1.4 \mathrm{~mm}$ thickness), both sides of the plate $(0.8 \mathrm{~mm}$ and $1.8 \mathrm{~mm}$ Thickness) Holes with significant tearing of solder joints, as shown in Figure 7 (c). Using the welding parameters of test 6 , the quality of the solder nuggets of the solder joints was acceptable.
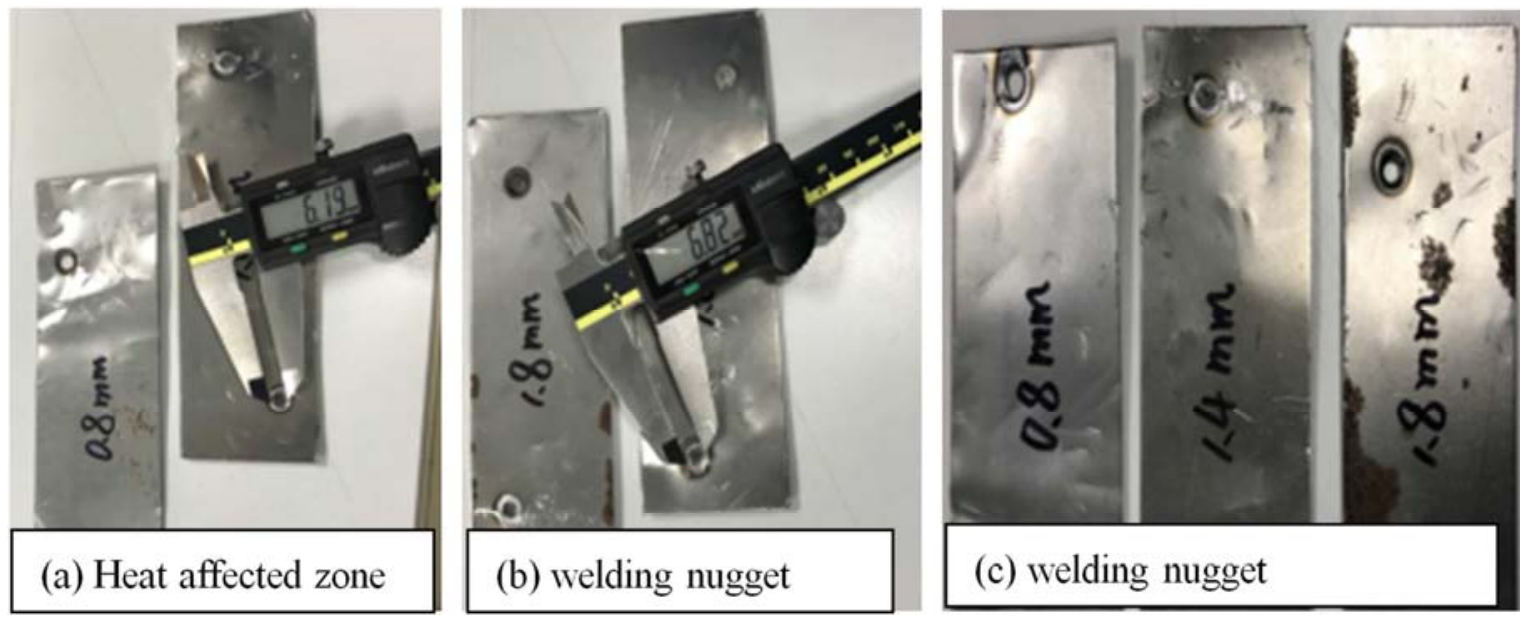

Figure 7. Nugget size and of test 6.

The actual working conditions of all parts overlap are more complex than that of the welding test piece. The data of the test 6 that passed the test is used to carry out the welding experiment on the manufacturing vehicle, and the hammer and chisel are used at the three-layer welding point $(0.8 \mathrm{~mm}+1.4 \mathrm{~mm}+1.8 \mathrm{~mm})$ for the non-destructive test, lift the chisel $30^{\circ}$ up and down, no welding is found in the solder joints, and the surface of the sheet metal was free from burrs and cracks. The quality of the non-defective solder joints of the manufacturing vehicle was acceptable, as shown in Figure 8.

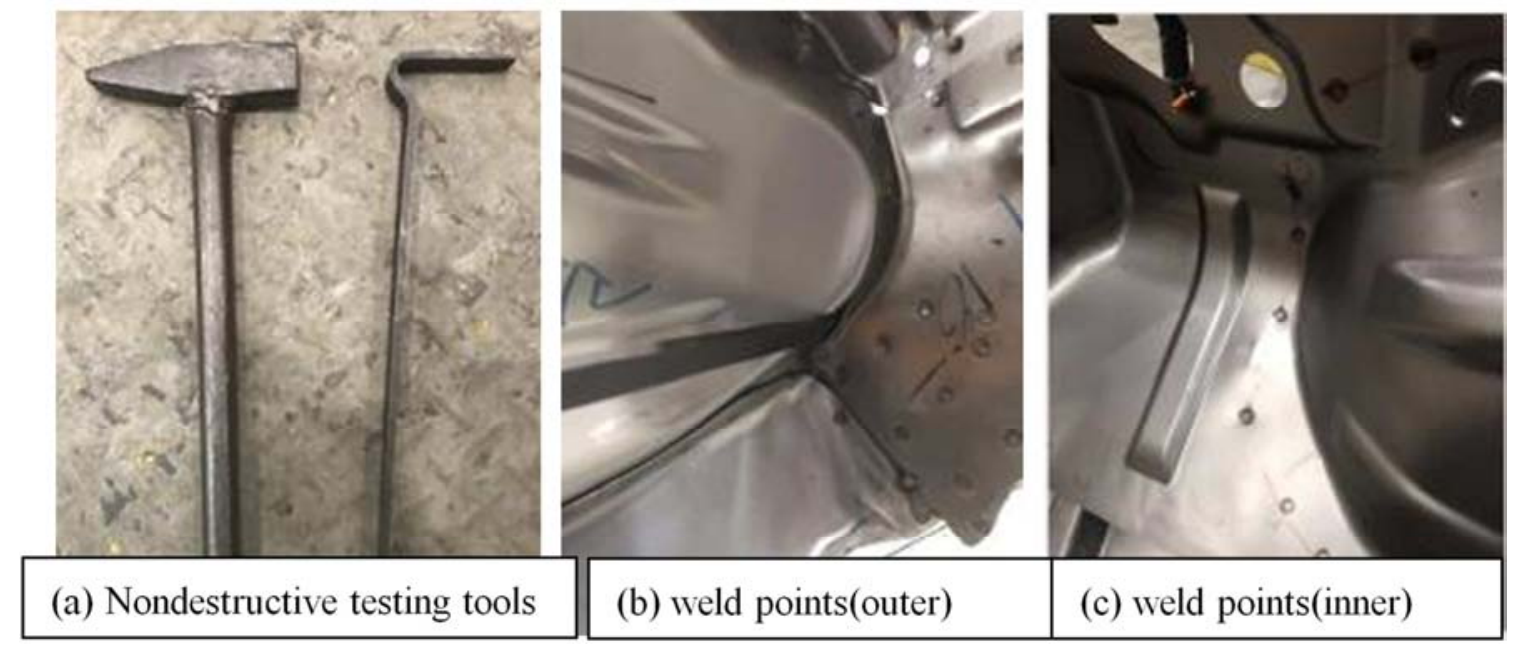

Figure 8. Actual non-destructive solder joint quality.

According to the quality requirements of resistance spot welding of SAIC-GM-Wuling, it is necessary to conduct full-destructive testing on the body joints on a regular basis. The joints in the front body area of this model were subjected to a full-destructive test. There were solder nuggets on both sides of the welded joints, cracks appeared on both sides of the sheet, and the quality of the solder joints was acceptable, as shown in Figure 9. 


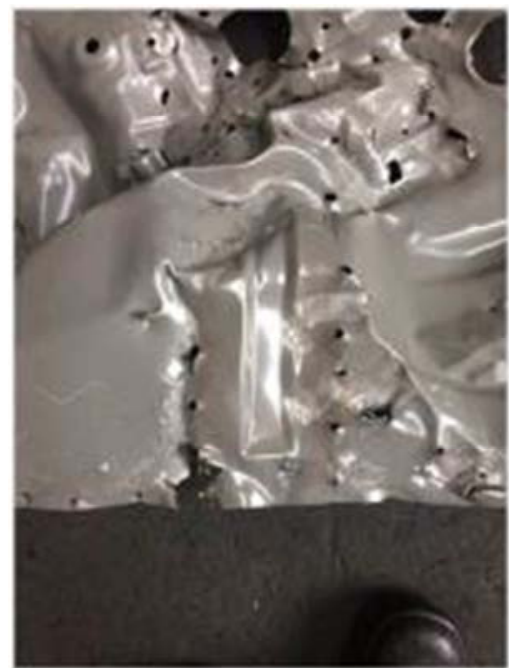

\section{Conclusion}

Obtained the resistance spot weld nugget dimensions with pulses of 1, 2 and 3, taking into account comprehensively, 3 pulse welding parameters, welding current 8.8/11.1/9.6KA, welding time $5 / 19 / 5 \mathrm{CY}$, electrode pressure $3 \mathrm{KN}$, The diameter of the nugget between the overlapping plates of each layer was $\geq \varphi 6 \mathrm{~mm}$. It is suitable for lap welding of plates with different thickness of $0.8 \mathrm{~mm}+1.4 \mathrm{~mm}+1.8 \mathrm{~mm}$.

In this paper, taking the left front beam and front panel lap joint as an example, it is expounded that when encountering the overlap between the two-layer board and the three-layer board, the welding process parameters for the three-layer board overlap should be selected preferentially which could solve the problem of welding nugget from the solder joints, hence provides a new idea and method for other automobile manufacturers.

\section{References}

[1] Shen Jie, Lin Haolei, Zhang Yansong, etc. Bad strength thick three layer board the control method of resistance welding molten nuclear dimension [J]. Journal of welding, 2011 (1): $33-36$

[2] Schreiber S. Investigation into three-member welding [J]. Welding and Cutting, 2001, 53:252-259.

[3] Cai Hongneng, Wang Yasheng, Zhang Zhanwei, Yang Hongwei. Automotive steel sheet resistance welding process parameter optimization selection method [J]. Journal of materials engineering, 2016. The supplement 1:30. 4-309.

[4] Sun Haitao, Wang Fengjue, Ma Qiang. Thick electrode pressure on three layers of ultra high strength steel sheet resistance welding quality analysis $[\mathrm{J}]$. The influence of hot working process, 2017. 2, 46 (3): 235-237.

[5] NielsenCV, FriisKS, ZhangW, et al. Three-sheet spot welding of advanced high-strength steels [J]. Welding Journal, 2011, 90 (2):32-40
[6] Cao Haipeng, Zhao Xihua, Zhao He. Aluminum alloy resistance spot welding process intelligent design $[\mathrm{J}]$. Journal of welding, 2005, 26 (2): 21-24.

[7] Wang Hongliang, Wang Ting, Xu Guocheng. Stainless steel urban rail passenger car body resistance spot welding quality monitoring [J]. Journal of welding technology, 2010, 33 (10) 6:60-62.

[8] Liu Chang, Guo Zhongning, Mo Binghua. Numerical simulation of resistance spot welding process technology research progress and application [J]. Mechanical and electrical engineering, 2010, 33 (9): 6 to 18-68.

[9] Yuan Shaobo, Tong Yangang. The application of spot welding technology in automobile industry $[\mathrm{J}]$. Electric welding machine, 2005. 2, 35 (2) 26 to 30.

[10] Qiu Ranfeng, Shi Hongxin, Zhang keke, Zhu Jinhong, Li jianjun. Car body with aluminium alloy and steel resistance spot welding dissimilar materials technology research status quo of [J]. Electric welding machine, 2010. 5, 40 (5): 150-154.

[11] Wu Song, Wang min, Cheng Xuanting, Wu Jiayuan, Sun You. Aluminum alloy resistance spot welding research situation and industrial application [J]. Journal of spot welding machine, 2013. 9, 43 (9): 10 to 16 .

[12] Qiu Chaoxin, Fang Ping, Cui Junhua, Guo Zhenghua, He Rong. Expert system for resistance spot welding technology research and development [J]. Journal of welding technology, 2014. 9, 43 (9): 44-46.

[13] Gozzi J, Olsson A, Lagerqvist O. Experimental investigation of the behavior of extra high strength steel [J]. Experimental Mechanics, 2005, 45 (6): 533-540.

[14] Mohanty P S, Gruzleski J E. Mechanism of grain refinement in aluminum [J]. Acta Metallet Mater, 1995, 43 (5):2001-2012.

[15] Johnsson M, BackerudL, Sigworth GK. Study of themechanism of grain refinement of aluminum after additions of $\mathrm{Ti}$ and $\mathrm{B}$ containing master alloys $[\mathrm{J}]$. Metallurgical Transactions A, 1993, 24 (2):481-491. 